\title{
Marco Nuti, Balzac, Dostoevskij e l'“alea" del gioco
}

\section{Marco Stupazzoni}

\section{(2) OpenEdition}

\section{Journals}

\section{Edizione digitale}

URL: http://journals.openedition.org/studifrancesi/9597

DOI: 10.4000/studifrancesi.9597

ISSN: 2427-5856

\section{Editore}

Rosenberg \& Sellier

\section{Edizione cartacea}

Data di pubblicazione: 1 décembre 2007

Paginazione: 679

ISSN: 0039-2944

Notizia bibliografica digitale

Marco Stupazzoni, «Marco Nuti, Balzac, Dostoevskij e l" alea" del gioco», Studi Francesi [Online], 153 (LI I III) | 2007, online dal 30 novembre 2015, consultato il 09 janvier 2021. URL: http://

journals.openedition.org/studifrancesi/9597 ; DOI: https://doi.org/10.4000/studifrancesi.9597

Questo documento è stato generato automaticamente il 9 janvier 2021.

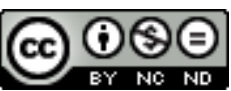

Studi Francesi è distribuita con Licenza Creative Commons Attribuzione - Non commerciale - Non opere derivate 4.0 Internazionale. 


\title{
Marco Nuti, Balzac, Dostoevskij e l' alea" del gioco
}

\author{
Marco Stupazzoni
}

\section{NOTIZIA}

MARCO NUTI, Balzac, Dostoevskij e l'“alea” del gioco, in «Linguae et. Rivista di lingue e culture moderne», Università degli studi di Urbino, Facoltà di Lingue e letterature straniere, 2005, n. 2, pp. 77-88.

1 La dimensione ludica e, in particolare, la categoria del gioco d'azzardo (l'alea secondo la definizione di Roger Caillois) rivestono, soprattutto nel romanzo dell'Ottocento, un'importanza alquanto significativa non soltanto dal punto di vista letterario, ma anche sotto la prospettiva filosofica e ideologica. Ne La Peau de chagrin di Balzac e ne Il Giocatore di Dostoevskij, la sala da gioco rappresenta a tutti gli effetti la metafora della vita, in cui l'uomo - il giocatore - isolandosi all'interno di uno spazio delimitato, fuori dal tempo e dalla realtà, nega l'ordine gerarchico su cui si fondano la logica e la morale della società. Sacro o diabolico, osserva Nuti, «all'origine del fascino del gioco vi è dunque una dimensione che rasenta il soprannaturale proprio in virtù dello spazio illimitato del Possibile» (p. 83). La complessa problematica del gioco d'azzardo presente nei romanzi di due autori consente di individuare un punto di contatto comune tra le due opere: «nella letteratura de l'alea, osserva l'autore, non incontriamo giocatori felici»: morso dal cieco destino ludico, il giocatore «vede dissolvere la sua esigenza di razionalità e la coerenza del suo rapporto con il mondo, divenuto indecifrabile» (p. 87). 